Recibido: 02/10/2020 --- Aceptado: 29/01/2021 --- Publicado: 12/05/2021

\title{
LA COMUNICACIÓN DE LA SOSTENIBILIDAD COMO HERRAMIENTA DE VENTAS Y DE CAMBIO SOCIAL: FAST FASHION VS SLOW FASHION
}

\section{SUSTAINABILITY COMMUNICATION AS A SALES AND SOCIAL CHANGE TOOL: FAST FASHION VS SLOW FASHION}

\section{(D) (8) Carmen Cristófol Rodríguez¹: Universidad de Málaga. España. carcrir@uma.es}

Kalem Mcquillan: Universidad de Málaga. España. kalemmcquillan@gmail.com

Jesús Segarra-Saaavedra: Universidad de Alicante. España. jesus.segarra@ua.es

\section{Cómo citar el artículo:}

Cristófol Rodríguez, C., Mcquillan, K. y Segarra-Saaavedra, J. (2021). La comunicación de la sostenibilidad como herramienta de ventas y de cambio social: fast fashion vs slow fashion. Revista de Comunicación de la SEECI, 54, 1737. http://doi.org/10.15198/seeci.2021.54.e667

\section{RESUMEN}

El presente trabajo de investigación pretende acercar al lector el concepto de sostenibilidad y su evolución en la industria textil. Se hace especial énfasis en conocer las diferencias entre el fast fashion y el slow fashion y el uso del argumento de la sostenibilidad en redes sociales como herramienta de ventas y/o de cambio social. Las cuatro empresas de moda sobre las que se realiza la investigación son Zara, HM, Patagonia y Ecoalf. Esta investigación exploratoria analiza el contenido de las publicaciones de Instagram durante el mes de noviembre de 2019, período que coincide con la celebración anual de Black Friday y el mayor movimiento a nivel mundial contra el cambio climático hasta entonces ocurrido. El objetivo es identificar la comunicación de las acciones sostenibles que ponen en práctica estas marcas y cómo tratan de concienciar y transmitir a sus seguidores. Además se realizan dos

${ }^{1}$ Carmen Cristófol Rodríguez: Doctora en Comunicación y Licenciada en Publicidad y Relaciones Públicas (UMA). Participa como IP en Proyectos de Innovación Docente, como evaluadora en revistas de reconocido prestigio, y como miembro de tribunales de tesis y trabajos fin de máster. carcrir@uma.es 
entrevistas en profundidad a profesionales de Patagonia y Ecoalf, las dos empresas de slow fashion escogidas para esta investigación. Se concluye que Zara y HM utilizan la comunicación de la sostenibilidad como herramienta de ventas. No obstante, si se mira desde una perspectiva global, sigue siendo positivo ya que ayuda a dar visibilidad al problema y a educar y sensibilizar a los consumidores a nivel internacional

PALABRAS CLAVE: Sostenibilidad - Fast Fashion - Slow Fashion - Responsabilidad Social Corporativa (RSC) - Impacto Ambiental.- Instagram - Moda - Publicidad no convencional

\section{ABSTRACT}

This research investigation aims to bring the reader closer to sustainability and the evolution of the textile industry, placing greater emphasis on knowing how fast fashion differs from slow fashion and its use of sustainability as a marketing tool aimed at generating sales rather than social change. The 4 fashion companies on which the research is carried out are Zara, HM, Patagonia and Ecoalf. This research studies Instagram posts of the fashion brands mentioned before, during the month of November 2019, the same month in which Black Friday is celebrated and, up until now the month when the largest movement that fought against climate change around the world was held. This analysis aims to understand the sustainable actions that these companies take and how they communicate and educate their consumers. In addition to two personal interviews with professionals from Patagonia and Ecoalf, both slow fashion companies. As a result, this study confirms Zara and HM use sustainability as a sales tool and out of interest. However, if you observe this situation from a global perspective, it can still be considered positive as it helps to give visibility to the problem and educate consumers around the globe.

KEY WORDS: Sustainability - Fast Fashion - Slow Fashion - Corporate Social Responsibility (CSR) - Enviromental Impact - Instagram - Fashion - Non conventional advertising

\section{A COMUNICAÇÃO DA SUSTENTABILIDADE COMO FERRAMENTA DE VENDAS E DE MUDANÇAS SOCIAIS: FAST FASHION X SLOW FASHION}

\section{RESUMO:}

O presente trabalho de pesquisa pretende aproximar ao leitor o conceito de sustentabilidade e sua evolução na indústria têxtil. Se faz ênfase em conhecer as diferenças entre o fast fashion e o slow fashion e o uso do argumento da sustentabilidade nas redes sociais como ferramenta de vendas ou de mudanças sociais. As quatro empresas de moda que são realizadas a pesquisa são Zara, HM, Patagonia e Ecoalf. Esta pesquisa de caráter exploratório analisa o conteúdo das publicações do Instagram durante o mês de novembro de 2019, período que coincide 
com a celebração anual do Black Friday e o maior movimento a nível mundial contra a mudança climática até então ocorrida. $\mathrm{O}$ objetivo é identificar a comunicação das ações sustentáveis que estas marcas fazem e como tentam conscientizar e transmitir a seus seguidores. Além disso, foram feitos dois questionários em profundidade para profissionais da Patagonia e Ecoalf, as duas empresas de slow fashion escolhidas para esta pesquisa. Como conclusão se obteve que Zara e HM utilizam a comunicação da sustentabilidade como ferramenta de vendas. Pelo outro lado, se olharmos desde uma perspectiva global, continua sendo positivo já que ajuda a dar visibilidade ao problema e a educar e sensibilizar aos consumidores a nível internacional

PALAVRAS CHAVe: Sustentabilidade - Fast Fashion - Slow Fashion Responsabilidade Social Corporativa (RSC) - Impacto Ambiental - Instagram - Moda - Publicidade não convencional

\section{INTRODUCCIÓN}

La presente investigación está protagonizada por un movimiento cada vez más presente en la sociedad actual, por la cadena de efectos que causa a nivel global y la repercusión que tendrá en las generaciones futuras. Se trata de la sostenibilidad y específicamente el impacto de la misma en el sector de la moda. La sostenibilidad como concepto es una herramienta que la mayoría de las grandes corporaciones utilizan como estrategia de marketing y de ventas, y que, sin embargo, otras empresas, lo usan cada vez más como motor de cambio social. La industria de la moda es extremadamente amplia pero la vertiente más explotada es una de la que todos somos partícipes, la moda rápida o a la denominada fast fashion, que en palabras de Martínez Barreiro (2008):

se basa en la rapidez, y consiste en surtir y resurtir a los clientes con las diferentes prendas de vestir que marcan la moda, y al mismo tiempo, ha conseguido desarrollar una nueva modalidad de vestir, que une de un lado la dimensión de moda, con un bajo coste tanto económico como psicológico del consumo.

En su lado opuesto se encuentran otras ramas que han nacido como reacción a la insostenibilidad del fast fashion como es el slow fashion que es un movimiento concienciado con el medioambiente cuyo objetivo se centra en el consumo responsable de la ropa el green fashion, definido por Hallama, Ribo y Tudela (2011) como el uso por parte de un organismo de una ampliación selectiva de la información medioambiental positiva, que produce una imagen distorsionada y aposta tendenciosa a favor de los aspectos "verdes", interpretados como positivos por los consumidores; o el eco fashion. La industria de la moda es una de las más dinámicas, competitivas y con mayor crecimiento del mundo, de manera que influye en el sistema económico, social y medioambiental muy directamente (Sharda \& Mohan, 2012). Las empresas tienen una responsabilidad social que han de cumplir y hablar de la sostenibilidad en el contexto de la moda es un reto para ellos, ya que supone un gran compromiso con los stakeholders. Por eso las marcas que comunican

Revista de Comunicación de la SEECI. 2021, n 54, 17-37 
la sostenibilidad de cualquier manera, por que sea, deben responsabilizarse y actuar acorde a sus mensajes. De este modo, si las palabras no acompañan a las acciones puede causar un efecto contraproducente para su imagen. Esta es una de las razones por lo que la mayoría de las empresas de fast fashion han pospuesto abrazar la sostenibilidad hasta ahora, cuando la responsabilidad social y ambiental se ha convertido en indispensable.

Por otro lado, la globalización y el uso intensivo de las tecnologías de la información, así como el cambio en nuestra cultura empresarial y de consumo, han causado un nuevo modelo de empresa en la industria de la moda en la que el tiempo es el factor crucial (Ferreira, 2015), esto se ve reflejado en que las empresas están en una lucha continua de quién responde a la demanda en el menor tiempo posible. Este fenómeno a su vez es propio del fast fashion, cuyos ciclos son mucho más rápidos que los de la moda de pasarela (Scaturro \& Granata, 2010), un ejemplo de ello es el lanzamiento de nuevos productos al mercado, donde se ha pasado de la producción de dos colecciones anuales a la renovación semanal de Zara (Ferreira, 2015). A su vez, esta transformación es fruto del incremento progresivo de la cantidad de ropa fabricada y consumida a la vez que los precios han disminuido como consecuencia de requisitos de producción y condiciones laborales cada vez más bajos (Allwood, Søren, \& Rodríguez, 2006).

En efecto, el hiper-consumismo o la cultura de lo desechable guía hoy el rumbo de la industria. Este cambio en el modo de consumir supone un gran impacto medioambiental tanto por el aumento de la producción, como por la cantidad de residuos de ropa que se generan por el deshecho de la misma (Kozlowski, Bardecki, \& Searcy, 2012). Así pues, en respuesta a una sociedad cada vez más consumista nació la sostenibilidad como una de las soluciones a los problemas que han nacido de la globalización.

Cuando hablamos de "sostenibilidad" o de "reducir nuestra huella de carbono", muchos de nosotros probablemente hayamos escuchado el mantra de lo que llaman las tres R's: reducir, reutilizar, reciclar. Este mantra tiene su origen el Día mundial de la Tierra en 1970, cuando se mostró a los alumnos de los colegios como la solución al creciente problema de los residuos generados por los consumidores (Laseter, Ovchinnikov, \& Raz, 2010). Es un mensaje claro que recuerda los pasos a seguir para avanzar hacia un futuro más sostenible. No obstante, si hablamos de la industria de la moda, hay estudios donde se afirma que esto sólo será posible cuando todos los actores (diseñadores, anunciantes, fabricantes, vendedores $y$, lo más importante, consumidores) acepten la importancia de forjar una industria intencionalmente sostenible, responsable y dinámica (Scaturro \& Granata, 2010).

Mientras tanto, la sostenibilidad ha hecho que cada vez más empresas intenten adoptar diferentes estrategias "sostenibles" para obtener una ventaja competitiva en el mercado (Kumar, Rahman, Kazmi, \& Praveen, 2012), aun así cabe recordar que la sostenibilidad no genera el mismo impacto en los consumidores cuando se utiliza como una acción de ventas o marketing puntual, sino que será exitosa a largo plazo cuando se muestra que los valores forman parte de la razón de ser de la empresa. 
Uno de los objetivos del presente trabajo de investigación es mostrar esa comparativa.

En este mismo contexto, la necesidad de las empresas de proyectar una visión global se ha recalcado desde principios de los 90 . Ya entonces se veía cómo los consumidores no se acercaban solamente a la marca por sus productos y servicios (Villagra \& López, 2013), sino que tenía que haber una fuerza mayor. Una teoría que se ha trasladado a estudios en la actualidad, es el círculo de oro de Simon Sinek (2009), quien justifica la idea que todo líder ha de tener una visión global. Su teoría está compuesta por tres preguntas que se engloban una dentro de otra y con la cual demuestra como los grandes líderes inspiradores de la historia, ya sea Apple, Harley Davidson o Martin Luther King, tienen un patrón común, su misión responde al porqué. Las empresas deben plantearse las siguientes tres preguntas: por qué, cómo y qué.

Primero, todo empieza en el porqué. El porqué es tu propósito: tu motivación para actuar, tu causa o tu creencia; Luego, el cómo son tus principios: los procesos, las acciones específicas para realizar el porqué; y finalmente el qué son tus resultados, los productos o servicios que ofreces de forma tangible con el que muestras tu porqué o propósito (Sinek, 2009). Esta teoría se aplicará en el estudio de casos para demostrar cómo las acciones de las empresas que nacen del qué, no son valorados tan positivamente como las empresas que nacen por actuar frente a una causa o creencia. Las empresas de fast fashion que vamos a analizar no cumplen con el círculo de oro, ya que se centran en el qué y el cómo principalmente. En cambio, Patagonia u otras empresas de slow fashion son un ejemplo de marcas que nacen desde una visión de sostenibilidad.

En definitiva, este trabajo de investigación pretende relacionar estos conceptos y, específicamente, analizar la construcción de identidades y algunas marcas corporativas de moda para demostrar si su comunicación se asemeja a sus valores éticos y responsables. Se realizará mediante el análisis de las actividades de comunicación y marketing de las empresas seleccionadas y donde se pretende identificar y comparar si las acciones "sostenibles" que desarrollan reflejan sus valores, siendo usadas como herramienta de cambio social o herramienta estratégica de ventas.

Según Cristofol, Alcalá y Fernández (2018), "Instagram es la aplicación que actualmente está de moda" entre los Millenials, y por tanto es la red social escogida para llevar a cabo esta investigación, si tenemos en cuenta que éstos son los principales consumidores de moda (Pérez y Luca, 2018).

\section{OBJETIVOS}

El foco de investigación de este trabajo es estudiar las acciones sostenibles que están llevando a cabo las marcas de moda, especialmente cómo las comunican y si verdaderamente lo hacen para ser más responsables socialmente o para conseguir una mayor ventaja competitiva en el mercado. 
Cristófol Rodríguez, C., Mcquillan, K. y Segarra-Saaavedra, J. La comunicación de la sostenibilidad como herramienta de ventas y de cambio social: fast fashion vs slow fashion

Generales:

- Conocer cómo las distintas marcas de moda comunican la sostenibilidad en redes sociales.

Específicos:

- OE1. Profundizar en el concepto de sostenibilidad como movimiento ambiental, social y político en las marcas de moda.

- OE2. Diferenciar las marcas de fast fashion y slow fashion desde un punto de vista comunicacional, analizando su comunicación en las redes sociales.

- OE3. Conocer la comunicación de la sostenibilidad que llevan a cabo cuatro marcas de moda en sus perfiles de Instagram desde el 1al 30 de noviembre de 2019.

Como primera hipótesis, se planteó si las acciones de sostenibilidad en las empresas de fast fashion son usadas con fines comerciales y para beneficiar a la imagen de su marca.

Como segunda hipótesis se planteó si la creciente preocupación por el cambio climático en la sociedad ha forzado a las empresas de fast fashion a comunicar acciones de responsabilidad con el medio ambiente, aunque esto no se refleje en los valores de la marca

\section{METODOLOGÍA}

Se realiza el análisis de las publicaciones de los perfiles de Instagram de cuatro marcas de moda, de las cuales dos son de fast fashion y dos de slow fashion, a lo largo de un periodo de un mes. Con el objetivo de estudiar su comunicación y lenguaje visual con respecto a sus valores corporativos y su postura con respecto a la sostenibilidad. Este análisis abarca dos vertientes:

- Análisis denotativo de las publicaciones, centrándose en las imágenes, palabras clave y hashtags referidos a la sostenibilidad y la RSC (Responsabilidad Social Corporativa).

- Análisis connotativo de los resultados para ver "mas allá" de lo que muestran e interpretar de manera subjetiva si utilizan la sostenibilidad como herramienta de cambio social o herramienta estratégica de ventas.

Como apoyo, todas las publicaciones se han analizado en base a una ficha de análisis de elaboración propia, partiendo de los conceptos planteados por Villagra y López (2013), quienes confirman que las empresas responsables incluyen en su identidad corporativa (misión, visión y valores) discursos que se relacionan directamente con la ética, responsabilidad social y sostenibilidad, alineándose con las nuevas demandas sociales. Se estudian los valores de las cuatro marcas y con la ficha de análisis se observa si comunican para educar o vender. 
Con respecto a la ficha de análisis de contenido de las publicaciones de Instagram, se ha elaborado la siguiente tabla, con un ejemplo, para recopilar la información y facilitar el análisis posterior:

Tabla 1. Matriz de análisis y ejemplo

\begin{tabular}{|c|c|c|c|c|c|c|c|}
\hline \multicolumn{7}{|c|}{ Análisis denotativo } & $\begin{array}{c}\text { Análisis connotativo/ } \\
\text { interpretativo }\end{array}$ \\
\hline $\begin{array}{l}\text { Fecha } \\
\text { de } \\
\text { publicac } \\
\text { ión }\end{array}$ & Marca & $\begin{array}{l}\text { Tipo } \\
\text { de } \\
\text { conten } \\
\text { ido }\end{array}$ & $\begin{array}{l}\text { Palabras } \\
\text { clave } \\
\text { referidas } \\
\text { a la } \\
\text { sostenibil } \\
\text { idad }\end{array}$ & $\begin{array}{l}\text { Palabras } \\
\text { clave } \\
\text { referidas a } \\
\text { las } \mathrm{RSC}\end{array}$ & $\begin{array}{l}\text { Hashtags } \\
\text { referidos a } \\
\text { la } \\
\text { sostenibilid } \\
\text { ad }\end{array}$ & $\begin{array}{l}\text { Imagen } \\
\text { referida a } \\
\text { la } \\
\text { sostenibil } \\
\text { idad }\end{array}$ & $\begin{array}{c}\text { Notas para facilitar el } \\
\text { análisis de resultados: } \\
\text { ej. ¿Está utilizando la } \\
\text { sostenibilidad para } \\
\text { concienciar a los } \\
\text { consumidores? ¿Tiene } \\
\text { un fin estratégico de } \\
\text { ventas? ¿Está llevando a } \\
\text { cabo una acción } \\
\text { puntual? }\end{array}$ \\
\hline $\begin{array}{c}01 / 12 / 2 \\
019\end{array}$ & $\begin{array}{c}\text { Patago } \\
\text { nia }\end{array}$ & $\begin{array}{c}\text { Image } \\
\mathrm{n}\end{array}$ & $\begin{array}{c}1 . \\
\text { Impacts } \\
\text { of } \\
\text { climate } \\
\text { change } \\
2 . \text { Ever- } \\
\text { increasin } \\
\text { g } \\
\text { pressures } \\
\text { on water } \\
\text { supplies } \\
3 . \\
\text { Conserva } \\
\text { tion }\end{array}$ & $\begin{array}{l}\text { indigenous } \\
\text { peoples'anc } \\
\text { estral rights }\end{array}$ & $\begin{array}{c}\text { \#climatech } \\
\text { ange }\end{array}$ & Si & $\begin{array}{c}\text { En esta publicación } \\
\text { Patagonia está tratando } \\
\text { un problema específico } \\
\text { sobre la conservación y } \\
\text { el impacto del cambio } \\
\text { climático en la población } \\
\text { indígena }\end{array}$ \\
\hline
\end{tabular}

Fuente: Elaboración propia.

Se escogió investigar el mes de noviembre por que iba a ser un mes donde las empresas tenían la oportunidad y usaron las redes sociales como una plataforma para llegar a los públicos, participar en los movimientos ambientalistas que surgían de manera global y llevar acciones que tengan como fin el cambio en la sociedad.

Por último, se realiza una investigación cualitativa utilizando la herramienta de la entrevista en profundidad a profesionales de las marcas en cuestión, para responder a preguntas acerca del rumbo de la industria textil, los planes de sostenibilidad y responsabilidad social corporativa, las acciones que desarrollan, su visión global y las expectativas de futuro. En el caso de Ecoalf, fue Jorge Delgado, encargado de Gestión de cadena de suministro, quien respondió a las preguntas de entrevista por correo electrónico y por otro lado, fue el Manager de gestión de cadena de producción en cuanto a trazabilidad y bienestar animal de Patagonia, quien cedió a hacer una entrevista vía Google Hangouts. En el caso de Patagonia, además, por motivos de sus políticas de privacidad y comunicación, la entrevista no pudo ser 
grabada sino transcrita durante la llamada y a posteriori las respuestas tenían que ser aprobadas por el entrevistado (del cuál no podemos dar su nombre) para poder ser publicadas.

\section{RESULTADOS}

\subsection{Análisis de contenido}

Para el procedimiento del análisis de contenido se ha elegido estudiar los perfiles de Instagram de 4 marcas de moda, dos de ellas pertenecientes al fast fashion: Zara y HM y dos pertenecientes al denominado movimiento slow fashion: Patagonia y Ecoalf, durante el mes de noviembre de 2019. La razón por la que se escogió este mes fue porque coincide con la famosa celebración del Black Friday, celebrado el 29 de noviembre en el 2019, una fecha en la que se fomenta el consumismo a grandes escalas. Pero a su vez, en esa misma fecha millones de personas alrededor del mundo fueron partícipes de la mayor protesta contra el cambio climático de la historia. Además, una gran proporción de las personas que participaron fueron niños, preocupados y luchando por su futuro, este cambio fue en gran parte desencadenado por los esfuerzos de la activista y pionera del movimiento global "School strike for climate", Greta Thumberg. Los manifestantes escogieron esta fecha para tomar una posición frente al Black Friday, ya que es considerado el día del año donde más ropa es vendida con el objetivo de ayudar a concienciar a los ciudadanos en uno de los días más consumistas del año. Por ejemplo, en solo EE.UU. se registraron 6.22Billones en compras online (Carlisle, 2019)

Este análisis se realiza desde dos perspectivas, un análisis denotativo-formal, más objetivo, y otro connotativo-interpretativo, aportando un punto de vista subjetivo sobre lo que transmiten las publicaciones de cada marca estudiando las imágenes o videos y el pie de foto de cada uno. Los datos del análisis están recogidos en una tabla de elaboración propia estudiando todas las publicaciones que estas marcas subieron a sus perfiles de Instagram a lo largo del mes en cuestión.

\subsubsection{Zara}

En primer lugar, en cuanto al análisis denotativo, durante el mes de noviembre Zara hace un total de 51 publicaciones. Los tipos de publicaciones fueron 36 imágenes, 14 de videos y 1 texto. A lo largo de este mes solo hubo 1 día (21/11/2019) donde sus publicaciones hicieron referencia a la sostenibilidad en cierta medida. Este día publicaron 3 imágenes promocionando la colección "Recycle" (reciclado en español). En cuanto a las palabras que hacen referencia a la sostenibilidad en el pie de foto se repiten las palabras: recycle, new life, recovered $y$ enviroment. Y sobre responsabilidad social corporativa en las publicaciones menciona como los productos son recuperados, lavados, clasificados y testados, colaborando con el reciclaje, usando procesos para reducir el consumo de agua y energía. Los únicos dos hashtags que utilizan son \#joinlife y \#recycle en las 3 publicaciones. Esto se resume en que solo un $5,9 \%$ de todas las publicaciones del mes de noviembre hacen referencia al tema en cuestión. Igual que solo un 5,9\% usan palabras

Revista de Comunicación de la SEECI. 2021, n 54, 17-37 
sostenibles, palabras de RSC y hashtags sobre la sostenibilidad. Y un 1,96\% utiliza una imagen referida a la sostenibilidad, en el caso de Zara se trata de 1 video donde se relata cómo funciona el proceso de reciclaje en las fábricas.

Por otro lado, para el análisis connotativo hemos extrapolado los siguientes datos sobre la naturaleza de las imágenes de las publicaciones: un $63 \%$ se clasifican como imágenes de interior (sesión de fotos), un $21 \%$ de exterior (entorno urbano) y por último $12 \%$ son imágenes tomadas al aire libre o con la naturaleza presente. Esto nos da a entender que la mayoría de sus imágenes son tomadas en sesiones de fotos para promocionar los productos y las nuevas colecciones, buscando siempre la venta. Se puede apreciar a través de sus redes sociales que esta marca tiene características propias del fast fashion: la frecuencia de publicaciones es de 1,7 veces diarias y en la gran mayoría se muestra un nuevo artículo perteneciente a una nueva colección, lo cual refleja la velocidad y capacidad de producción de la marca.

Cabe destacar que Zara se especializa más en ropa de uso diario, urbana, de noche, etc. que ropa deportiva o de uso en la naturaleza, lo que explicaría la falta de imágenes al aire libre. Es curioso que varias de las imágenes en la naturaleza promocionan unos zapatos de piel animal por lo que muestran que no tienen ningún compromiso con el bienestar animal (Animal Fairtrade).

Con respecto a las 3 publicaciones donde hablan de su colección reciclada el debate gira en torno a darle una nueva vida a las plumas que se usan para las chaquetas. En el video y el pie de foto se describe el proceso que llevan a cabo para conseguirlo y comunican cómo cumplen con los procesos de ahorro energético y de agua para cuidar al medio ambiente. En el video se muestra la propia factoría donde supuestamente se realiza este proceso. La sensación que transmite el video es parecida a la de la película "Charlie y la fábrica de chocolate", está muy romantizado y se muestra un entorno pacífico y de tranquilidad, una de las razones es por qué no se muestra a nadie trabajando en la fábrica. Esto hace preguntarse, si están ocultando a los trabajadores y la ubicación de la fábrica para no mostrar las condiciones laborales en las que desarrollan su trabajo, el grupo social, etc.

Por último, a pesar de sacar la línea "Recycle" que pretende mostrar su compromiso frente al cambio climático, el día 29 de noviembre, Zara no hizo ninguna publicación. Entendemos por ello que no tiene un compromiso real con el medio ambiente y que evita publicar en esa fecha para no generar ningún tipo de reacción por parte del público, ya que además coincide con el Black Friday. En contraposición, podemos pensar que es positivo que no hicieran referencia al Black Friday en sus publicaciones sin fomentar de más el consumismo.

\subsubsection{HM}

En primer lugar, con respecto al total de publicaciones, HM publica considerablemente más que Zara, sumando un total de 86 publicaciones el mes de noviembre, que se traduce a una media de 2,9 veces diarias. De estas 72 fueron imágenes y 14 videos. En el transcurso del mes solamente hubo 1 día (25/11/2019)

Revista de Comunicación de la SEECI. 2021, n 54, 17-37 
en el que se hizo referencia a la sostenibilidad, donde promocionan los "concious skincare products", una línea de belleza consciente. Como datos podemos sacar que un $1,2 \%$ de las publicaciones del mes de noviembre están relacionadas con la sostenibilidad, usando palabras que categorizamos como sostenibles. Por otra parte, en ninguna ocasión se utiliza un hashtag sobre el tema en cuestión, ni una imagen o video que aborde el problema.

En segundo lugar, con respecto al análisis interpretativo, se ha de decir que un $72 \%$ de las imágenes o videos son tomados en interior, que se componen de fotografías de artículos individuales o de sesiones de fotos con modelos y en muchos casos utilizan como recurso a famosos como Kendal Jenner o Chiara Ferragni. Además, un $26 \%$ del contenido es creado en el exterior donde suelen promocionar una nueva colección o para que las personas vean los artículos en un entorno real y cotidiano. Por último, en solo un $2 \%$ de las publicaciones se mostraba la naturaleza.

Por otro lado, hay que añadir que la única vez donde publican sobre la nueva línea de belleza consciente, no incluyen en el pie de foto ningún tipo de información sobre la línea, el porqué es consciente y como ayuda al planeta. Dado esto, parece un caso de greenwashing, donde tratan de dar la impresión que son productos sostenibles con el uso de palabras asociadas (como consciente) pero con un fin comercial.

Al mismo tiempo, a lo largo del mes lanzan nuevos productos y colecciones para Navidad, casi un mes antes de la festividad. Se puede concluir, por tanto, que promocionan excesivamente el consumismo a pesar de ser la época en que más se compra y como consecuencia, se llega a picos de contaminación y residuos altísimos.

Por último, añadir que el día 29 de noviembre publicaron 3 imágenes, pero no hacían referencia al movimiento que estaba surgiendo en todo el mundo, sino que promocionan nuevos artículos.

\subsubsection{Patagonia}

Patagonia se diferencia mucho de las otras tres marcas analizadas por diversos factores que explicaremos a continuación. Tiene una frecuencia de publicación más pausada, un total de 27 publicaciones en noviembre, una media de 0,9 veces diarias. El tipo de contenido de las publicaciones es de 20 imágenes, 6 vídeos y 1 gráfica con texto. Encontramos que hacen referencia a la sostenibilidad y la RSC en los pies de imágenes en un $27 \%$ de las ocasiones. En una única ocasión utilizan un hashtag, y es el de \#wornwear, un programa o servicio de reparaciones y reciclaje de productos que ofrece Patagonia.

Las palabras que utilizan en los pie de fotos abarcan muchos temas como puede ser el lugar de producción de sus artículos (local), los certificados de compromiso con el medio ambiente y los animales (Paris Climate Accord), el material del que están hechos los productos (organic cotton, natural fabrics, used-garnments), la técnica que utilizan para fabricar y diseñarlos (wornwear, recrafted, recy/ced, renorepair), y el comportamiento o valores que intentan educar (passing things down). 
Cristófol Rodríguez, C., Mcquillan, K. y Segarra-Saaavedra, J. La comunicación de la sostenibilidad como herramienta de ventas y de cambio social: fast fashion vs slow fashion

Podemos añadir que en un $26 \%$ de ocasiones la imagen o video tiene una referencia muy directa con la sostenibilidad, ya sea porque fuera un video explicativo sobre cómo crean ropa a partir de botellas recicladas o la imagen con un texto del CEO de Patagonia donde comunica su preocupación por que EE.UU no forme ya parte del Tratado de París que protege y lucha contra el cambio climático.

En cuanto al análisis interpretativo vemos que todas las imágenes de Patagonia son tomadas en la naturaleza, haciendo deporte o trabajando al aire libre, reflejando los valores de la marca. En ninguna imagen se promociona un producto en particular, sino que son fotografías muy naturales de personas cotidianas dando uso a los productos en situaciones reales. De hecho, la gran mayoría de fotos son grandes planos generales donde toma más protagonismo la naturaleza. La persona suele salir en un segundo plano y los artículos ocupan el último plano, ya que en la mayoría de las ocasiones no se ve el logo de la marca o la foto es tomada a tanta distancia que no se puede distinguir si lleva un producto de Patagonia. También, en muchas ocasiones el pie de foto tampoco hace alusión a los productos sino a la actividad deportiva que se está realizando o al destino donde se toma la foto.

También cabe añadir que tras analizar las imágenes en un 30\% de las ocasiones promocionan un producto o colección de manera directa y cuando lo hacen informan sobre la manera en la que se ha creado el producto, los materiales o sus características, distintivas del slow fashion, como la durabilidad por ejemplo.

Por otro lado, el tipo de contenido también nos indica la transparencia que tiene la empresa con sus acciones y sus consumidores, tienen fuertes valores y usan su voz para generar cambio. Como la declaración anteriormente mencionada de su CEO donde manifiesta su creciente preocupación por que EEUU no forme parte del Acuerdo de París o en los videos educativos donde tratan de concienciar a los consumidores sobre el ciclo de vida de sus productos.

Con respecto a los videos, solamente 1 de los 6 hace referencia directa a los consumidores de los productos de Patagonia, se publicó el día 15/11/2019, y en vez de hablar de la producción, el video trata la filosofía de la marca. Es un video que sigue una narrativa "storytelling" donde dos amigas de unos 15 años cuentan su relación con el deporte, la naturaleza y la importancia de no necesitar tanto, si no de pasar lo aprendido de generación en generación y cómo siempre han hecho lo mismo con su ropa. Los productos de Patagonia tienen una historia, tienen marcas que son recuerdos de la infancia, son prendas que llevaron sus madres y enfatizan sobre el valor añadido que la marca le da a la ropa.

Otro de los videos trata sobre el servicio mencionado anteriormente, Worn Wear, aquí los propios trabajadores de esta fábrica de reparaciones de Patagonia hablan sobre la historia que hay detrás de Worn Wear, el slow fashion, darle una nueva vida a la ropa, reutilizar, recrear, etc. $Y$ hacer todo esto sin necesidad de usar otro recurso del planeta que no sea el recurso de las personas y su mano de obra. Todos comparten la misma filosofía, que es la opuesta al fast fashion; son trabajadores que

Revista de Comunicación de la SEECI. 2021, no 54, 17-37 
le dan importancia a las cosas y quieren hacer un mundo mejor. De hecho, en este caso Patagonia se une con Swey, una marca especializada en la reconstrucción de artículos usados, para hacer una nueva colección de las prendas que no eran reparables. Como resultado de usar hasta el último recurso, podías comprar una chaqueta formada a partir de 6 chaquetas usadas. Otro de los videos que publican es una continuación del descrito anteriormente, este continúa hablando sobre Worn Wear pero enfatizando el impacto de la industria de la moda en el medio ambiente, trata de ser un video educativo para justificar el valor de Worn Wear.

Similar a estos dos videos, también publican un video en formato de ilustración sobre sus "better sweaters" (mejores sudaderas) donde explican el estudio del ciclo de vida del producto comenzando por el usar botellas reciclables y residuos de vertederos que se descomponen para luego convertir en materiales con los que crear las sudaderas.

Por último, el día 29 de noviembre publican otro video informativo donde lanzan un programa de donaciones que estará abierto desde ese día hasta el 31 de diciembre, abarcando desde Black Friday hasta el final de la Navidad. Con este vídeo, buscan que los consumidores regalen a sus seres queridos donaciones a movimientos y organizaciones que luchan por el cambio climático y el medio ambiente, en vez de salir a comprar a las tiendas. Básicamente pretenden que las personas sean más conscientes a la hora de comprar o regalar en la época más consumista del año.

\subsubsection{Ecoalf}

El comportamiento de Ecoalf es muy diferente al de Patagonia. La frecuencia de publicación de Ecoalf es muy similar a la de Patagonia, con un total de 32 publicaciones, lo cual se traduce a 1,06 veces al día. De éstas, 2 fueron videos, 1 texto y 29 publicaciones fueron imágenes, de las cuales 2 mostraban al equipo de Ecoalf. Las 6 últimas publicaciones, en la semana del Black Friday y Strike for climate, constaban de imágenes con estadísticas del efecto de la industria textil en el planeta para promover la educación de las personas sobre el tema.

Por otro lado, en el $100 \%$ de las publicaciones utilizan alguna palabra que haga referencia a la sostenibilidad o a la RSC. Observamos que Ecoalf se centra mucho en la fabricación de sus propios productos y la medida en que lo hacen. Su slogan es "there is no planet $\mathrm{B}^{\prime \prime}$ y se repite en casi todas las publicaciones. También hacen hincapié en la innovación, la preocupación por las generaciones futuras, proteger el planeta, reciclar, reducir la huella de carbono y ecológica o con algunos productos comunican que son veganos y certificados por PETA. En el $97 \%$ de las publicaciones utiliza el hashtag \#becausethereisnoplanetb, en solo una ocasión no usan hashtag y en otra usan el hashtag \#RecyclingBlackFriday que es cuando publican el texto con las palabras "Act now" el día 10/11/2019 para informar sobre la huelga contra el cambio climático el día 21 de noviembre en Berlín y el día 29 en Madrid donde ellos se unirán. También queda señalar que en un $31 \%$ de ocasiones las imágenes hacen 
referencia a la sostenibilidad de manera directa y que en las demás ocasiones (69\%) las imágenes están promocionando directamente un producto.

Ahora, si hablamos del análisis connotativo Ecoalf en líneas generales promocionan mucho sus productos, ya que suelen ser imágenes realizadas en una sesión de fotos, en un entorno profesional donde pretenden mostrar las características del producto o modelos llevando los productos, a diferencia de Patagonia que muestran un estilo de vida. Aun así, en todas las ocasiones Ecoalf es transparente con los consumidores explicando los materiales sostenibles a partir de lo que están hechos los productos. Por otra parte, en las ocasiones en las cuales promociona las colecciones de niños, enfatizan sobre generar cambio para las generaciones futuras, y en todos los casos los niños llevan ropa con el slogan "there is no planet $\mathrm{B}^{\prime \prime}$.

En líneas generales comunican su compromiso por ayudar al planeta y encontrar soluciones innovadoras, servir como medio de difusión y para educar al mundo, además ayuda a cientos de instituciones educativas y fundaciones que luchan por proteger al medio ambiente y cuidar el planeta. Otro de los temas recurrentes a lo largo del mes de noviembre es el de RecyclingBlackFriday, donde muestran su postura opuesta a un día que únicamente promueve el consumismo y deciden no participar como marca en el Black Friday, si no salir a las calles a manifestarse contra el cambio climático en los dos locales que tienen en Madrid y Berlín. El día 24 de noviembre, unos días antes de la celebración del Black Friday publican un video educativo donde enseñan imágenes de las grandes repercusiones que tiene la industria de la moda en el medio ambiente, fotos de las factorías, la polución, etc.; y donde explican por qué no van a participar.

Desde ese día hasta final de mes, Ecoalf publica una serie de imágenes con estadísticas sobre la realidad de la industria textil y siempre acompañado del mensaje "educate yourself". Podemos ver como la marca presenta su compromiso por el medio ambiente y durante esa semana no publica nada promocionando sus productos sino intentando educar a los consumidores sobre la repercusión que tienen nuestras acciones por mínimas que parezcan. Para ejemplificar esto, utilizaron estadísticas como "La población de media solo usa una misma prenda 7 veces" o "Se necesitan 2700 litros de agua para hacer una camisa de algodón, aproximadamente lo que una persona bebe en 2.5 años".

\subsection{Entrevistas en profundidad}

Para completar la investigación sobre el análisis de contenido de los perfiles de Instagram de las cuatro marcas, se procede a la realización de entrevistas en profundidad. El objetivo era el de conocer internamente la visión que tienen los empleados sobre la marca, su compromiso con la naturaleza, su opinión sobre el fast fashion, la percepción de los consumidores, los cambios en la moda industria textil y el impacto en generaciones futuras. 
El diseño de la investigación planteaba cuatro participantes, uno de cada marca analizada, para poder hacer una comparativa de las empresas de fast fashion y slow fashion frente a la sostenibilidad. No obstante, a pesar de contactar con ellos, se pudo contactar con Ecoalf y Patagonia, quienes estaban dispuestos a colaborar, previo compromiso de confidencialidad.

La entrevista pasó por una serie de fases: en primer lugar el entrevistador realizó una introducción sobre la investigación a realizar, el motivo de la investigación, el objeto de estudio y los tipos de preguntas; segundo, el entrevistado explica el papel que desarrolla en la marca; y por último comienza la entrevista. En ocasiones el entrevistado responde varias preguntas de una vez.

A continuación se presentarán los resultados de Ecoalf y Patagonia frente a los siguientes valores:

\subsubsection{Valorar el ciclo de vida del producto}

Afirmativamente, el impacto ambiental que genera todo el ciclo de vida de los productos es algo de lo son conscientes ambas empresas e intentan mejorar continuamente. Ecoalf, en los últimos meses ha implementado medidas más precisas para controlar el impacto a nivel ambiental y social de sus prendas, de hecho en la próxima temporada se va a ver en los propios artículos, lo que supondrá más transparencia sobre el proceso e impacto de cada producto y dar más visibilidad para que los consumidores sean conscientes del efecto de la industria de la moda en el planeta.

En el caso de Patagonia, es una empresa que intenta asegurar que toda la cadena de producción cumpla con los requisitos y. certificaciones correspondientes, siempre acordes a lo que comunican y buscando minimizar el impacto continuamente. Además, la rama de Worn Wear, trata de preservar productos y materiales de calidad y mantenerlos en circulación. Además Patagonia tiene lo que es considerada la mayor fábrica de reparación textil en EE.UU para que los compradores puedan enviar los productos a reparar si se dañan con el tiempo. Aun así en esa fábrica solo cuenta con unos 80 trabajadores, lo cual refleja que los productos son muy alta calidad por que las reparaciones son mínimas.

\subsubsection{Valorar la opinión sobre el fast fashion}

Patagonia defiende que son una empresa pequeña en comparación con HM o Inditex que son gigantes del mercado. Si éstos por ejemplo hacen que solo un $5 \%$ de sus líneas de moda sean de materiales sostenibles, puede parecer poco en comparación con Patagonia cuyo porcentaje sería muchísimo mayor, pero hablando de manera global un 5\% en $\mathrm{HM}$ es mucho más que todo lo que hace Patagonia por el volumen de la empresa. Es más, en ningún momento, menosprecia a las empresas de fast fashion, si no que añade que, si empresas como éstas pueden mover el dedo, por muy mínimo que parezca, tiene un gran impacto a nivel global y eso es algo que hay que tomarlo como algo positivo para la industria. Por otro lado, el entrevistado defiende que, aunque las razones por las que las empresas de fast fashion lleven a

Revista de Comunicación de la SEECI. 2021, n 54, 17-37 
cabo acciones sostenibles pueda tener un fin diferente a Patagonia, continúa siendo algo positivo ya que lleva estos temas al mercado comercial y tiene la capacidad de darle voz a asuntos de manera más rápida que Patagonia, que podría tardar años en conseguirlo por tener menos capacidad.

Ecoalf, al igual que Patagonia también afirma que toda acción que se lleve a cabo siempre será positiva. Pero Ecoalf añade que estas acciones se tienen que desarrollar con criterio, es necesario pensar en toda la cadena de producción y no únicamente en un aspecto o acción. Afirma que probablemente se trate de greenwashing pero que si las empresas ven que estas acciones sostenibles se traducen en ventas y que es aceptado positivamente por los clientes, acabarán invirtiendo recursos en ser más sostenibles y comprometerse con el medio ambiente, que sería positivo. Por último sugiere que los clientes también tienen que tomar conciencia y saber tener criterio a la hora de comprar para no caer en estrategias de greenwashing, de hecho pone como ejemplo que si en una etiqueta pone poliéster reciclado es del $5 \%$ y lo demás es poliéster convencional, no marca mucho la diferencia, pero también es trabajo de los consumidores educarse y ser responsables comprando.

\subsubsection{Valorar el factor precio}

En cuanto al factor precio ambos entrevistados responden prácticamente igual a la pregunta, los consumidores tienen que concienciarse y entender que si una camiseta cuesta 5 euros, como es el caso de las empresas de fast fashion, alguien o algo está pagando por el valor restante del producto. Se trata de poner un precio justo, que cumpla con unos estándares que protejan al medio ambiente y a todas las personas involucradas en la cadena de valor del producto. Si todas las empresas fueran transparentes y los consumidores pudieran ver en sus etiquetas todo lo que hay detrás de una sola prenda el pagar haría que los precios fueran más justificables.

Otro tema que también comparten ambas empresas es la de educar a la población para reducir su frecuencia de compra y llevar a cabo un consumo responsable. Tenemos que aprender a vivir con menos y de mayor calidad: nadie necesita tener 7 abrigos en el armario, y si las personas llevan esto a la práctica la industria de slow fashion podría sustentarse a largo plazo, ya que estarían felices comprando un abrigo de calidad a un precio justo y sabiendo que tiene una durabilidad mucho mayor.

\subsubsection{Valorar el factor calidad}

En la siguiente pregunta de entrevista se pretende ver si con la concienciación sobre los principios de moda sostenible se podría cambiar la actitud consumista de la mayoría de las personas. Ambas marcas sostienen que la educación sobre la sostenibilidad es clave para cambiar los hábitos de las personas, pero que la industria de la moda es solo una parte de todo el espectro y es necesario aplicarlo en la medida de lo posible a todos los aspectos de nuestra vida cotidiana. 
Ecoalf además añade que para que esta adopción de mercado sea exitosa también hay que darle importancia al diseño y la calidad de las prendas, para que los consumidores puedan llevarlas con orgullo. Patagonia por otro lado, defiende que sus diseños no varían mucho de temporada en temporada ya que buscan hacer diseños atemporales y la durabilidad es uno de los factores a los que más importancia da la marca. De hecho, Nicholas Allen cita "la chaqueta que ha pasado varias veces por la fábrica de reparaciones es probablemente mi prenda favorita, porque tiene historia y carisma".

Tanto Patagonia como Ecoalf, afirman que ninguno es perfecto, al final del día son una empresa que venden productos y estos tienen un impacto en el medio ambiente. Pero dentro de "lo malo" intentan encontrar soluciones innovadoras que consuman menos agua, menos energía, etc., servir de ejemplo a otras empresas y educar a las personas. En el caso de Patagonia, no se consideran ni siquiera una empresa de moda sino activistas que luchan por cuidar nuestro planeta. Ambas están de acuerdo en que vestirse es una necesidad del ser humano, pero Ecoalf recalca "han pasado ya muchos años desde que se "cubrió" esa necesidad y ahora nos encontramos en un excesivo consumo de prendas". En conclusión, se necesitan unos ciudadanos responsables que valoren la calidad frente a la cantidad.

\subsubsection{Valorar el coste de producción}

Por último, se pregunta si el slow fashion puede ser comercialmente viable para personas de menos capacidad financiera y si podría el slow fashion satisfacer a la demanda de un futuro mercado consciente del medioambiente. Ecoalf asegura que una de las razones por la que los precios son más elevados en el presente es porque la industria la domina el fast fashion y son los que salen ganando, pero si viviéramos en un mercado consciente sobre el medio ambiente y se le premiara a los que intentan hacer bien, se estandarizarían los costes de producción y se volvería más accesible para el mercado. Aun así, se reitera sobre el consumo: no se necesitan 7 abrigos si no 1 de calidad que dure varios años y defiende como a pesar del esfuerzo inicial, a largo plazo se ahorra al no desecharlo y comprar uno nuevo.

En estas líneas, Patagonia dice como todo el mundo recuerda su campaña "Dont buy this jacket", no compres esta chaqueta, fue una de las acciones que probablemente más impacto tuvo y la idea que había detrás era exactamente eso, si no lo necesitas, no vayas a comprarlo. También argumenta que hay algo que no pueden controlar las marcas y es cómo las personas deciden consumir tus productos, pero lo que ellos intentan comunicar siempre es: "no lo compres si no lo necesitas y si tienes una prenda y funciona, repáralo; y si tienes que comprar algo, compra una prenda ya usada o reciclada, intenta agotar todas las posibilidades antes de hacer una compra impulsiva". Y por último, si vas a ir a comprar, considera usar los mejores materiales que puedas y comprar en un lugar donde cuiden el bienestar ambiental y animal en todos los aspectos de la cadena de suministro. Concluye que si cuesta un poco más, en vez de comprar 10 camisetas a 7 euros, puedes comprar 1 camiseta a 35 euros, sabiendo que está hecha con algodón orgánico y en una fábrica de comercio justo. 
Cristófol Rodríguez, C., Mcquillan, K. y Segarra-Saaavedra, J. La comunicación de la

sostenibilidad como herramienta de ventas y de cambio social: fast fashion vs slow fashion

\section{DISCUSIÓN Y LIMITACIONES}

A través de la presente investigación se ha profundizado en la comunicación de la sostenibilidad en las marcas de fast fashion y slow fashion, centrándose en el estudio de cuatro marcas conocidas Zara, HM, Patagonia y Ecoalf, dos de cada tendencia de moda respectivamente, y en su uso de la comunicación de la sostenibilidad como herramienta de marketing o cambio social. La información recopilada y los análisis realizados permiten dar respuestas a las hipótesis planteadas al comienzo de la investigación.

Como primera hipótesis, se planteó si la comunicación de las acciones de sostenibilidad en las empresas de fast fashion son usadas con fines comerciales y para beneficiar a la imagen de su marca. Se comprueba, por tanto, que estas empresas, en especial Zara y HM, tienen presente la sostenibilidad de alguna manera en su plan de negocio por mínima que parezca. Ambas empresas han lanzado una línea que se clasifica dentro de la sostenibilidad, por lo que se puede decir que está surgiendo un cambio de mentalidad en los consumidores y las grandes empresas buscan satisfacer esa demanda y las necesidades de unos consumidores cada vez más concienciados por el medio ambiente. Visto que el porcentaje de publicaciones 0 referencias en torno a la sostenibilidad fue mínima en el caso de ambas marcas, a pesar de analizar un mes de gran importancia para el medio ambiente y el cambio climático, ninguna se involucró ni le dio voz a la causa. Por esta razón, se confirma que después promocionen una línea sostenible se considera poco coherente y que tiene solamente un fin comercial, ya que no participan de manera activa. Este punto podría ser cuestionado si las empresas de fast fashion hubiesen estado disponibles para responder las preguntas de esta investigación. Tomamos su negativa como una respuesta que confirma la hipótesis inicial.

Asimismo, tal y como dan respuesta en las entrevistas de las empresas de slow fashion, el consumidor también tiene que ser responsable y ver que si una etiqueta dice que es reciclada, ha de tener juicio y saber cuándo es una cuestión de greenwashing. Por último, decir que ambas empresas coinciden en que cualquier acción que lleven a cabo las empresas de fast fashion, al final va a ser positiva para la industria de la moda y ayuda a abrir un camino cada vez más sostenible. Con la comunicación de estas acciones se da conocimiento y voz al mercado lo que es positivo globalmente.

Como segunda hipótesis se planteó si la creciente preocupación por el cambio climático en la sociedad ha forzado a las empresas de fast fashion a comunicar acciones de responsabilidad con el medio ambiente, aunque esto no se refleje en sus valores de marca. Tras la investigación realizada, se llega a la conclusión de que sí es cierto que estas empresas han visto la necesidad de adaptarse a las nuevas "tendencias" del mercado. La incorporación de líneas sostenibles no es algo que lleven haciendo Zara o HM desde que nacieron, no forma parte de los valores de la marca y solo ha aparecido en los últimos años debido a la creciente alarma social por el medio ambiente. Patagonia lo defiende demostrando que las empresas de slow

Revista de Comunicación de la SEECI. 2021, n 54, 17-37 
fashion no intentan competir los unos con los otros, sino que realmente buscan lo mejor para el planeta y que cada uno de manera individualiza intente reducir la huella de carbono. Patagonia afirma que bien es cierto que la sostenibilidad no forma parte del ADN de Zara o HM, pero que cada vez más comunican acciones de gran impacto, siendo capaces de mover la industria de manera mucho más rápida que Patagonia, por ejemplo, y es algo que debe ser valorado.

También se planteó cómo los públicos perciben la comunicación de las acciones sostenibles de HM o Zara. Como ya se ha mencionado, un consumidor informado puede que perciba que estas acciones son un caso de greenwashing o en el caso de un consumidor habitual de marcas de fast fashion sentir cierta gratificación por pensar que hace algo bien para el planeta. No se puede responder a esta pregunta con certeza ya que se no se ha hecho un análisis cualitativo de los consumidores de las marcas en cuestión. No obstante, las respuestas de las dos entrevistas dan a entender que, aunque no importa cómo perciban los públicos las acciones sostenibles de estas marcas, sino el hecho que se expongan a ellas cada vez que acudan a las tiendas tendrá algún tipo de repercusión, ya sea educativo, informativo, etc. Aun así, la solución al problema también está en que los consumidores aprendan a ser más responsables, llevando a cabo un consumo consciente y preguntarse a la hora de comprar un producto cuestiones como ¿Quién está pagando en la cadena de valor para que esta camiseta cueste 5 euros? ¿De qué productos está hecho esta camiseta? ¿Dónde se ha fabricado la camiseta? ¿Realmente, necesito esta camiseta o es un capricho?

Básicamente los consumidores también necesitan poner de su parte, las empresas pueden incitar la compra, pero la decisión final está en sus manos. La responsabilidad subyace en cada uno para intentar entender los intereses que hay detrás de cada acción y ser crítico. Los recursos del planeta son limitados y para controlar su gasto, los hábitos de consumo deberían transformarse en otros más lentos y aprender a vivir con menos para no comprometer a las generaciones futuras. Este es pilar fundamental de la sostenibilidad.

Por último, se cuestiona si existe una correlación entre la comunicación de las acciones sostenibles de las marcas de moda puntuales con tener un fin comercial y la comunicación de las acciones globales con un fin social. Con respecto a las empresas de slow fashion que se han estudiado y entrevistado para esta investigación, está claro que su visión va mucho más allá de solo vender. Ecoalf, por ejemplo, se muestra como una empresa de moda que sí promociona sus productos pero invierten en la innovación, tecnología, el diseño sostenible y la transparencia, para crear productos de material reciclado, de bajo impacto ambiental y respetuoso con los animales. Analizando sus redes se puede afirmar que se centran en la presentación de sus productos e informar sobre su producción. En cambio, Patagonia no promociona apenas sus productos, sino que comunica un estilo de vida, sus valores, el deporte, la naturaleza, necesitar lo básico para ser feliz. Se puede afirmar que su modelo de negocio gira más sobre una economía circular, no solo a la hora de fabricar los productos como Ecoalf, sino haciendo partícipes a los consumidores con medidas como la fábrica de reparaciones o su línea Worn Wear, como dice su página

Revista de Comunicación de la SEECI. 2021, nº 54, 17-37 
"Porque lo mejor que podemos hacer por el planeta es reducir el consumo y aprovechar más las cosas que ya poseemos".

En contraposición, en el caso de HM y Zara la frecuencia de publicación y de promoción de artículos de nuevas colecciones hace que una acción puntual como la publicación de la promoción de una gama o producto sostenible se quede en el olvido y se convierta en una estrategia más de venta. La falta de publicaciones que abordaran el tema del cambio climático o en el caso de HM la promoción continuada de la navidad, hace concluir que sus acciones sostenibles no tienen un propósito global si no un fin comercial.

Finalmente, como se ha explicado en ambas entrevistas, no se trata de luchar los unos con los otros. Queremos vivir en un planeta mejor y que nuestras acciones no comprometan a las generaciones futuras, es por ello por lo que toda acción por mínima que parezca tiene que considerarse como positiva.

\section{REFERENCIAS}

Allwood, J., Søren, L. \& Rodríguez, C. (2006) Well Dressed? The Present and Future Sustainability of Clothing and Textiles in the United Kingdom. Cambridge: University of Cambridge.

Carlisle, M. (2019) Millions Around The World Strike on Black Friday for Action on Climate Change. https://bit.ly/3dXgTWq

Cristofol Rodríguez, C., Alcalá Vidal, A., \& Fernández Pérez, L. (2018). Análisis comparativo de las aplicaciones Snapchat e Instagram: nuevas tendencias derivadas de su uso. Redmarka: revista académica de marketing aplicado, 20, 3976.

Fernández Sánchez, D. (2019). La moda sostenible, un nicho emergente dentro del sector textil Kozlowski, A., Bardecki, M. \& Searcy, C. (2012) Environmental Impacts in the Fashion Industry: A Life-Cycle and Stakeholder Framework", en The Journal of Corporate Citizenship, 45, 77 https://bit.ly/3gcxEhm

Ferreira Docampo, M. (2015). Moda Sostenible, presente y ¿futuro? Un estudio de casos. https://bit.ly/3dOeOvG

Hallama, M., Ribo, M. M., Tudela, S. R., \& Vendrell, G. C. (2011). El fenómeno del greenwashing y su impacto sobre los consumidores propuesta metodológica para su evaluación. Aposta. Revista de Ciencias Sociales, (50), 1-38.

Kumar, V., Rahman, Z., Kazmi, A. A. \& Praveen, G. (2012) Evolution of sustainability as marketing strategy: Beggining of new era. Prodedia. Social and Behavioral Sciences, 37, 482-489 https://bit.ly/2VyYSa3 
Laseter, T., Ovchinnikov, A. \& Raz, G. (2010) Reduce, Reuse, Recycle... or Rethink. Strategy + Business. https://bit.ly/3dT0xhb

Martínez Barreiro, A. (2008). La moda rápida: última transformación del sistema de la moda. Universidad Nova de Lisboa.

MODA, M., \& COMPETITIVA, U. H. (2003). Marketing ecológico

Pérez Curiel, C., \& Luque Ortiz, S. (2018). El marketing de influencia en moda. Estudio del nuevo modelo de consumo en Instagram de los millennials universitarios.

Scaturro, S. \& Granata, F. (2010). Ethics + Aesthetics = Sustainable Fashion. https://bit.ly/3dPKH73

Sharda, N. L. \& Mohan, V. K. (2012) Multifarious Approaches to Attain Sustainable Fashion. Nordic Textile Journal, 1, 31-37. https://bit.ly/38n7rKC

Sinek, S. (2009) Cómo los grandes líderes inspiran la acción. (TEDx). https://bit.ly/3geki4k

Villagra, N. \& López, B. (2013) Analysis of values and communication of the Responsible Brands. Corporate Brand strategies for sustainability. Comunicación y Sociedad, 26, 1, 196-221. https://doi.org/10.15581/003.26.1.201-226

\section{AUTORES:}

\section{Carmen Cristofol Rodríguez}

Doctora en Comunicación y Licenciada en Publicidad y Relaciones Públicas (UMA). Acreditada por ANECA como Profesor Ayudante Doctor, Profesor Contratado Doctor y Profesor de Universidad Privada. Investigadora en los grupos de investigación COMPUBES, IICCXXI (UA) y SEJ396 "Nuevas Formas Publicitarias y Nueva Economía". Socia de la AEIC (sección 7) y AIRPP. Ha participado en diversos Proyectos de Innovación Docente, tribunales de tesis y trabajos fin de máster. Es evaluadora de artículos de revistas de reconocido prestigio y ha compaginado durante más de doce años su actividad académica con la de profesional de los medios de comunicación en el Grupo Prisa. Su línea de investigación se centra en la comunicación de la moda, el marketing digital y el neuromarketing.

carcrir@uma.es

Orcid ID: https://orcid.org/0000-0001-9766-6500

Google Scholar: https://bit.ly/2J5Hyo3

ResearchGate: https://bit.ly/2IZG9iM

Scopus: 55753876500

Academia.edu: https://bit.ly/2V3fIQf 


\section{Kalem McQuillan}

Es Graduada en Publicidad y Relaciones Públicas por la Universidad de Málaga.

\section{Jesús Segarra-Saavedra}

Doctor en Comunicación Audiovisual y Publicidad, Premio extraordinario de doctorado y Licenciado en Publicidad y Relaciones Públicas por la Universidad de Alicante (UA). Docente y profesor de Comunicación en UA. Investigador en los grupos "Comunicación y grupos específicos" (COMPUBES) de la UA, "Comunicación y Sociedad Digital" (COSODI) de UNIR, "Gestión de la Comunicación Estratégica" (GCE) de la Universidad Técnica Particular de Loja (Ecuador), en el Observatorio de Ficción Española y Nuevas Tecnologías (OFENT) y en el Observatorio Iberoamericano de la Ficción Televisiva (OBITEL). Editor técnico adjunto de Revista Mediterránea de Comunicación, editor adjunto de Revista Health and Addictions y socio de AE-IC, SLCS, PLATCOM, RELAIP y RIdHC.

Orcid ID: http://orcid.org/0000-0001-9420-5258

Google Scholar: https://bit.ly/2YSrOGS

ResearchGate: https://bit.ly/2EIvskD

Scopus: https://bit.ly/2Dd090C

Academia.edu: https://bit.ly/2G7BUSE 